\title{
The Effect of Bedside Handover Sheet on Nursing Care in Hepatobiliary Surgery
}

\author{
Wang Xiao-lan ${ }^{1,2}$, Li Wei-rong ${ }^{1,2}$, Zhu Hua-lan ${ }^{1,2}$, Shi Yan-hua ${ }^{1,2}$, Liu Cui-qing ${ }^{1,2, ~ * ~}$ \\ ${ }^{1}$ Department of Hepatobiliary Surgery, The First Affiliated Hospital, Jinan University, Guangzhou, People's Republic of China \\ ${ }^{2}$ School of Nursing, Jinan University, Guangzhou, People's Republic of China
}

Email address:

liucq2018@sina.com (Liu Cui-qing)

${ }^{*}$ Corresponding author

\section{To cite this article:}

Wang Xiao-lan, Li Wei-rong, Zhu Hua-lan, Shi Yan-hua, Liu Cui-qing. The Effect of Bedside Handover Sheet on Nursing Care in Hepatobiliary Surgery. American Journal of Nursing Science. Vol. 7, No. 3, 2018, pp. 84-87. doi: 10.11648/j.ajns.20180703.11

Received: March 27, 2018; Accepted: April 23, 2018; Published: May 18, 2018

\begin{abstract}
Objective To explore the clinical effectiveness of bedside handover sheet and verbal handover note in hepatobiliary surgery. Methods A comparative study was conducted between the bedside handover sheet designed for patients in department of hepatobiliary surgery and verbal handover note. N-A handovers from January to June in 2017 in the Department of First Affiliated Hospital of Jinan University were included into the controlled group and N-A handovers from July to December were into the observation group. Handover time, unclear handovers, handover omission and adverse events in the two groups were observed and recorded. Results N-A handover duration in the observation group was $28.1 \pm 3.57 \mathrm{~s}$ and no unclear handover was observed. The occurrence of handover omission and adverse events in the observation group was much lower than that of the controlled group $(\mathrm{P}<0.05)$ but nurse satisfaction was much higher. Conclusions Handover sheet of hepatobiliary surgery is of much more advantages than verbal handover note thus are worth of being generalized.
\end{abstract}

Keywords: Nursing, Handover, Clinical Application, Sheet Bedside Handover

\section{Introduction}

Handover is a routine forum of nursing communication at change of shifts, when nurses take breaks and following patient transfers across ward spaces, when a nurse hands over the patient information to another nurse and describes the implemented and needed nursing interventions at the bedside, which can help to improve nursing quality $[1,2]$. High-quality bedside handover can effectively reduce nursing error to provide nursing security for the patients. At present, different hospitals may have different handover styles, which may also have different impact on nursing quality. A comparative study between verbal handover note and bedside handover sheet of hepatobiliary surgery was conducted to improve quality of bedside handover and to explore specific handover style fit for different departments.

\section{Data and Methods}

\subsection{General Data}

There are 46 beds in the Department of Hepatobiliary Surgery and 21 nurses who are all females, aged from 18-45. Years of working range from 1 to 24 . Educational background structure: 8 people are undergraduates, 12 people graduated from junior college, 1 from technical secondary school. N0 nurses: 6, N1 nurses: 8, N2 nurses: 5, N3 nurses: 2. Verbal handover notes (recorded in notebook) were employed for 982 patients from January to June in 2017 in the controlled group. In the observation group specifically-designed handover sheets for hepatobiliary surgery were applied to 986 patients from July to December. There is no significant difference in the total number and condition of patients, and age, title, educational background and years of working of the nurses between the two groups. 


\subsection{Methods}

Verbal handover notes in which open-ended recording method was adopted and there was no fixed content or format were taken during the bedside handover shift in the controlled group. In this case, a nurse records the information of the patients voluntarily at the dictation of another nurse. However, handover sheets designed by professional doctors and nurses for patients in the Department of Hepatobiliary Surgery according to their clinical characteristics and under the consideration of comprehensive nursing measures were adopted in the observation group. Before the handover shift, the handover nurse according to the sheet content should conclude and check the information of the patients that need to be handed over to the relief nurse especially some important phenomena such as emotional rage and communication difficulty. The handover nurse and relief nurse stand on the same side of the patient bed and the handover nurse reports to the relief nurse based on the sheet while the relief nurse take notes on the corresponding column of the sheet simply with a tick or other character signs. For example, "remove drainage tube" can be simply recorded as "remove". The handover sheet and its application notes are referred to the Table 1.

Table 1. Bedside Handover Sheet for Hepatobiliary Surgery Date.

\begin{tabular}{lllllll}
\hline $\begin{array}{l}\text { Bed } \\
\text { Number/Name }\end{array}$ & $\begin{array}{l}\text { Duration } \\
\text { /Shift }\end{array}$ & Operation & $\begin{array}{l}\text { Operation } \\
\text { tomorrow }\end{array}$ & $\begin{array}{l}\text { Preoperative } \\
\text { Preparation }\end{array}$ & $\begin{array}{l}\text { Wound } \\
\text { dressing }\end{array}$ & $\begin{array}{l}\text { abdominal } \\
\text { distention/Abdominal } \\
\text { pain }\end{array}$ \\
\hline & $\mathrm{A}$ & & & \\
$\mathrm{P}$ & $\mathrm{N}$ & & & \\
\hline
\end{tabular}

Table 1. Continued

\begin{tabular}{|c|c|c|c|c|c|c|c|}
\hline $\begin{array}{l}\text { Bed } \\
\text { Number/Name }\end{array}$ & $\begin{array}{l}\text { Gastric tube / } \\
\text { urinary catheter }\end{array}$ & $\begin{array}{l}\text { T tube/PTCD tube/ } \\
\text { nasobiliary tube }\end{array}$ & $\begin{array}{l}\text { MR/CT/ } \\
\text { B-ultrasonography }\end{array}$ & CVC/PICC tube & $\begin{array}{l}\text { Gastroscopy } \\
\text { / enteroscopy }\end{array}$ & $\begin{array}{l}\text { Special } \\
\text { drugs }\end{array}$ & $\begin{array}{l}\text { Other } \\
\text { notices }\end{array}$ \\
\hline
\end{tabular}

Sheet filling description: Except in special circumstances, Vis used for operation, Operation tomorrow, preoperative preparation columns. Simply "Not" can be used when the preoperative preparation is not completed. Vis for dry and clean wound dressing. "Yes" is employed when there is abdominal distention or abdominal pain. As for the diet, $\sim$ is for liquid diet, - for semifluid diet and $\sqrt{ }$ for full diet. Drainage tube: $\sqrt{ }$ for normal situation and "remove" for removal of drainage tube. Other phenomena needed to be described can be recorded in the column of "Other notices".

\subsection{Outcome Measures}

Unclear handovers, handover omission, adverse events and nurse satisfaction during 6 months and $\mathrm{N}$-A handover duration of the $6^{\text {th }}$ month in the two groups were observed.

\section{Results}

\subsection{Comparison of the Handover Between the Two Groups}

It is shown that the $\mathrm{N}-\mathrm{A}$ duration of observation group is $28.1 \pm 3.57 \mathrm{~s}$, which is significantly lower than $35.6 \pm 3.24 \mathrm{~s}$ of controlled group. The difference is of statistical significance as shown in Table 2.

Table 2. Comparison of the Handover between the Two Groups.

\begin{tabular}{llll}
\hline Group & $\begin{array}{l}\text { Number of } \\
\text { cases }\end{array}$ & $\begin{array}{l}\text { Handover } \\
\text { number }\end{array}$ & $\begin{array}{l}\text { Handover } \\
\text { duration(s) }\end{array}$ \\
\hline Controlled group & 30 & 30 & $35.6 \pm 3.24$ \\
Observation group & 30 & 30 & $28.1 \pm 3.57$ \\
$t$ & 8.545 & & \\
$P$ & 0.000 & & \\
\hline
\end{tabular}

\subsection{Comparison of the Number of Adverse Events Between the Two Groups}

After 6 months of observation, it is found that the occurrence of adverse events of the observation group is lower than that of controlled group and the difference is statistically significant $(\mathrm{P}<0.05)$ as shown in Table 3.

Table 3. Comparison of the Number of Adverse Events between the Two Groups.

\begin{tabular}{lllll}
\hline Group & Total cases & $\begin{array}{l}\text { Adverse } \\
\text { events }\end{array}$ & $\begin{array}{l}\text { Handover } \\
\text { omission }\end{array}$ & $\begin{array}{l}\text { Unclear } \\
\text { handovers }\end{array}$ \\
\hline Controlled group & 928 & 9 & 10 & 8 \\
Observation group & 986 & 4 & 2 & 0 \\
$\chi^{2}$ & & 29.697 & & \\
$P$ & & 0.000 & & \\
\hline
\end{tabular}

\subsection{Nurse Satisfaction}

Application of the specialized sheet improves nurse satisfaction by highlighting key points, completely conveying handover information and avoiding the transmission of unnecessary information. The satisfaction rate before application is $87 \%$ while after application it is $97 \%$.

\section{Discussion}

Nursing handover system is one of the core nursing care systems. And bedside handover is a main style among the nursing handover styles, aiming at improving nursing care quality. Bedside handover is a kind of face to face communication [5-6]. Smeulers, et al. [3] suggested adopting face to face handover in order to improve the accuracy of information and reduce errors. Although verbal handover note is more convenient than verbal handover, the study found that 
the content in the verbal handover note is much more random and simpler and there are more omission and unclear handovers, which is related to the nurses' expression and nursing ability. And unclear handover increases nursing risk. Jane Bruton [7], et al. hold that standardized and structured handover in written form is conducive to the improvement of bedside handover quality. Specialist handover sheet for hepatobiliary surgery provides fixed handover content, key points so the relief nurse can just tick in the appropriate column or mark with a simple sign thus avoiding omission, unclear events, and reducing nursing risk, improving handover quality and effectively shortening handover duration [4]. The study shows that handover sheet can reflect the overall, individual and special nursing information of the dynamic condition of patients. The nursing staff can learn the patients' condition and clarify key nursing points according to the handover sheet to conduct preventive nursing work and effectively avoid and reduce nursing risk [8-11].

The results of this clinical study show that the N-A handover duration, handover omission, unclear handovers and nursing adverse events of observation group are significantly lower than those of the controlled group $(\mathrm{P}<0.05)$. The following conclusions can be achieved: 1) This method shortens the handover duration, because the verbal handover note takes $35.6 \pm 3.24 \mathrm{~s}$, while the handover sheet costs $28.1 \pm$ $3.57 \mathrm{~s}$, and the difference between the two is statistically significant $(\mathrm{P}<0.05)$. The verbal handover note requires relief nurse to currently take note of what the handover nurse say while handover sheet only requires ticking on the corresponding column, or simpler note such as "remove" for removing drainage tube, which can shorten handover duration and thus increasing the nursing time $[12,13]$; 2) it improves the handover quality. There is significant difference in handover omission and unclear handovers between the two groups. The quality of handover when adopting verbal handover note is strongly associated with experience and comprehensive quality of nurses. Experienced nurses may highlight key points and remind the relief nurse or low-seniority nurse of matters needing attention, while low-seniority nurses because of lack of experience, specialty knowledge and overall master of handover content are inclined to commit handover omission and unclear handovers, when the they are required to hand over much information verbally. Accordingly, nursing adverse events due to buck-passing or phone call to the handover nurse after the shift may appear. Handover sheet highlights key points, presents comprehensive and clear handover content, which is easy for nurses of all seniority to master thus avoiding omission and effectively improving the quality of handover; reduces the occurrence of adverse events. In the controlled group, 9 cases of nursing adverse events occurred within 6 months ( 2 cases of falls, 1 case of pressure sore, 2 cases of phlebitis, 2 cases of slipping of tube and 2 cases of omission of blood sugar monitoring). In the observation group, there appeared 4 cases of adverse events (one case of fall, phlebitis, slipping of tube and omission of blood sugar monitoring).

\section{Conclusions}

The specialist handover sheet covers major nursing problems in the department of hepatobiliary surgery and can reflect the dynamic condition of individual and special nursing information. So the nurses can assess the patients' condition according to the contents of the sheet to avoid omission of assessment and to eliminate safety problems caused by inappropriate assessment and thus reducing the occurrence of adverse events. This study indicates that the handover sheet for hepatobiliary surgery is of much more advantages than verbal handover notes and thus is worth generalizing.

\section{References}

[1] Sabet, S. R., Moattari, M., Nasrabadi, A. N., Momennasab, M., \& Yektatalab, S. (2014). Challenges of nursing handover: a qualitative study. Clinical Nursing Research, 28(3), L925-L927.

[2] Paula Eustace, R. N., Ba, P. M. L., Ba, M. J. C., Rnc, B. K., \& Mid, D. P. M. (2011). Communication at the bedside to enhance patient care: a survey of nurses' experience and perspective of handover. International Journal of Nursing Practice, 17(2), 133-140.

[3] Smeulers M, Lucas C, Vermeulen H. Effectiveness of different nursing handover styles for ensuring continuity of information in hospitalised patients[J]. Cochrane Database Syst Rev, 2014, 6(6):CD009979.

[4] Tobiano, G., Chaboyer, W., \& Mcmurray, A. (2013). Family members' perceptions of the nursing bedside handover. Journal of Clinical Nursing, 22(1-2), $192-200$.

[5] Liu, W., Manias, E., \& Gerdtz, M. (2012). Medication communication between nurses and patients during nursing handovers on medical wards: a critical ethnographic study. International Journal of Nursing Studies, 49(8), 941-52.

[6] Chaboyer, W., Johnson, J., Hardy, L., Gehrke, T., \& Panuwatwanich, K. (2010). Transforming care strategies and nursing-sensitive patient outcomes. Journal of Advanced Nursing, 66(5), 1111-9.

[7] Bruton, J., Norton, C., Smyth, N., Ward, H., \& Day, S. (2016). Nurse handover: patient and staff experiences. British Journal of Nursing, 25(7), 386 .

[8] Welsh, C. A., Flanagan, M. E., \& Ebright, P. (2010). Barriers and facilitators to nursing handoffs: recommendations for redesign. Nursing Outlook, 58(3), 148.

[9] Cheryl Holly EdD RN, \& Eileen B Poletick DNP RN. (2014). A systematic review on the transfer of information during nurse transitions in care. Journal of Clinical Nursing, 23(17-18), 2387-2396.

[10] Chaboyer, W., Johnson, J., Hardy, L., Gehrke, T., \& Panuwatwanich, K. (2010). Transforming care strategies and nursing-sensitive patient outcomes. Journal of Advanced Nursing, 66(5), 1111-9.

[11] Starmer, A. J., Spector, N. D., West, D. C., Srivastava, R., Sectish, T. C., \& Landrigan, C. P. (2017). Integrating research, quality improvement, and medical education for better handoffs and safer care: disseminating, adapting, and implementing the i-pass program. Joint Commission Journal on Quality \& Patient Safety, 43(7), 319. 
[12] Chui, M. A., \& Stone, J. A. (2012). The prescription handoff in community pharmacy: a study of its form and function. Journal of the American Pharmacists Association, 52(6), e161-e167.
[13] Mardis, T., Mardis, M., Davis, J., Justice, E. M., Riley, H. S. \& Donnelly, J., et al. (2016). Bedside shift-to-shift handoffs: a systematic review of the literature. Journal of Nursing Care Quality, 31(1), 54-60. 